V. De Sanctis

M. Galimberti

G. Lucarelli

E. Angelucci

M. Ughi

D. Baronciani

P. Polchi

C. Giardini

B. Bagni

C. Vullo

\section{Pubertal development in thalassaemic patients after allogenic bone marrow transplantation}

Eur J Pediatr (1993) 152:993-997
V. De Sanctis

Department of Paediatrics,

Arcispedale S. Anna Hospital,

I-44100 Ferrara, Italy
In reviewing our paper we have unfortunately found that we made two mistakes:

1. The scale of testosterone values (Fig. 1) should be from 0 to 1000 $\mathrm{ng} / \mathrm{dl}$, instead from 0 to 100 as shown in the figure.
2. The last sentence of "Results" in "Sequential clinical and basal hormonal data" should read as follows:

In contrast, a progressive reduction of FSH levels was observed in 9 girls, but in all of them the levels remained above the normal range. 